\title{
Can Low SHBG Serum Concentration Be A Good Early Marker Of Male Hypogonadism In Metabolic Syndrome?
}

This article was published in the following Dove Press journal: Diabetes, Metabolic Syndrome and Obesity: Targets and Therapy

\author{
Piotr Jarecki (D) \\ Waldemar A Herman (iD) ${ }^{2}$ \\ Elżbieta Pawliczak (D) ${ }^{3}$ \\ Katarzyna Lacka $\mathbb{D}^{4}$
}

'Student Scientific Club of Endocrinology, Poznan University of Medical Sciences, Poznań, Wielkopolskie, Poland;

${ }^{2}$ Outpatients Clinic of Endocrine Diseases, Wschowa, Lubuskie, Poland; ${ }^{3}$ Department of Nephrology, Transplantology and Internal Medicine, Poznan University of Medical Sciences, Poznań, Wielkopolskie, Poland;

${ }^{4}$ Department of Endocrinology, Metabolism and Internal Medicine, Poznań University of Medical Sciences, Poznań, Wielkopolskie, Poland
Correspondence: Katarzyna Lacka Department of Endocrinology, Metabolism and Internal Medicine, Poznan University of Medical Sciences, Poznań, Przybyszewskiego 49 60-834, Poland $\mathrm{Tel}+4861604905086$

Email kktlacka@gmail.com
Introduction: In men suffering from metabolic syndrome, accompanying insulin resistance may result in a lowering of sex hormone-binding globulin (SHBG) plasma levels and cause changes in their androgenic status.

Aim: The objective of the research was to assess selected androgens and SHBG plasma levels in males meeting diagnostic criteria for MS compared to healthy males.

Patients and methods: The group consisted of 65 men aged between 40 and 70 years old fitting IDF metabolic syndrome criteria and 84 controls. Dehydroepiandrosterone (DHEA) and its sulphate (DHEA-S), total and free testosterone and SHBG serum levels were evaluated. Calculated free and bioavailable testosterone were estimated using an algorithm proposed by the International Society for the Study of the Aging Male.

Results: Men diagnosed with MS showed a statistically significant decrease in plasma levels of DHEA in comparison to healthy ones: 11.579 (8.39-15.56) vs $14.014(9.611-17.125) \mathrm{ng} / \mathrm{mL}$; $\mathrm{p}=0.0350$, SHBG: $47.46(35.78-62.83)$ vs $71.965(54.45-91.56) \mathrm{nM} / \mathrm{L} ; \mathrm{p}<0.0001$ and total testosterone: $5.2(3.8-6.5)$ vs $6.3(5.4-8.25) \mathrm{ng} / \mathrm{mL} ; \mathrm{p}=0.0001$ (values presented as a median with Q1-Q3).

Conclusion: The results suggest that SHBG is a good early marker for metabolic dysregulation in MS, considering its strength of association and significance is comparable to, or better than, those of MS criteria.

Keywords: MS, DHEA, testosterone, CRP, cholesterol, androgens

\section{Introduction}

The changes in the biology of an aging male are complicated and not yet fully understood. A growing number of publications show a link between age-related hormonal changes and prevalence of metabolic syndrome (MS). The decrease in androgens (independent of the cause: e.g. through aging or usage of gonadotropinreleasing analogs $)^{1}$ as well as in SHBG has been linked with visceral obesity and exacerbation of aspects of $\mathrm{MS}^{2-4}$

With age, the natural production of adrenal androgens and testosterone decreases, and this, as a consequence, negatively affects the risk of developing not only MS but also atherosclerosis. ${ }^{5}$

\section{Aim Of Study}

The intention of this study was to explore the changes in serum androgen balance, both adrenal and gonadal (DHEA [dehydroepiandrosterone], DHEA-S 
[dehydroepiandrosterone-sulfate], SHBG [sex hormonebinding globulin], FT [free testosterone], TT [total testosterone], c-FT [calculated free testosterone] c-BAT [calculated bioavailable testosterone]), in a given age group among patients with metabolic syndrome and comparing them to healthy individuals.

\section{Patients And Methods}

Recruitment for the study was carried out in an outpatient endocrinology clinic in rural regions of southwestern Poland, presented in Figure 1, from a city of less than 15,000 inhabitants plus neighboring villages. Controls were acquired from the same population and the same age groups. The patients were chosen in such a way that they were exactly $40,50,60$ or 70 years old. The group consisted of 65 patients (11 forty-year-olds, 19 fifty-year-olds, 18 sixty-year-olds and 17 seventy-year-olds). The control group was comprised of 84 (23 forty-year-olds, 21 fifty-year-olds, 20 sixty-year-olds and 20 seventy-year-olds) healthy participants matching the test group, recruited from the same population. Controls following any particular diets like gluten-free diet, vegetarians, vegans or suffering from any preexisting diseases or known genetic disorders were excluded.

The inclusion criteria were meeting the IDF metabolic syndrome criteria, which means central obesity understood as waist circumference $>94 \mathrm{~cm}$ plus meeting 2 out of $4 \mathrm{MS}$ criteria, namely triglycerides $\geq 150 \mathrm{mg} / \mathrm{dL}$ or treatment for this lipid abnormality, glucose $\geq 100 \mathrm{mg} / \mathrm{dL}$ or previously

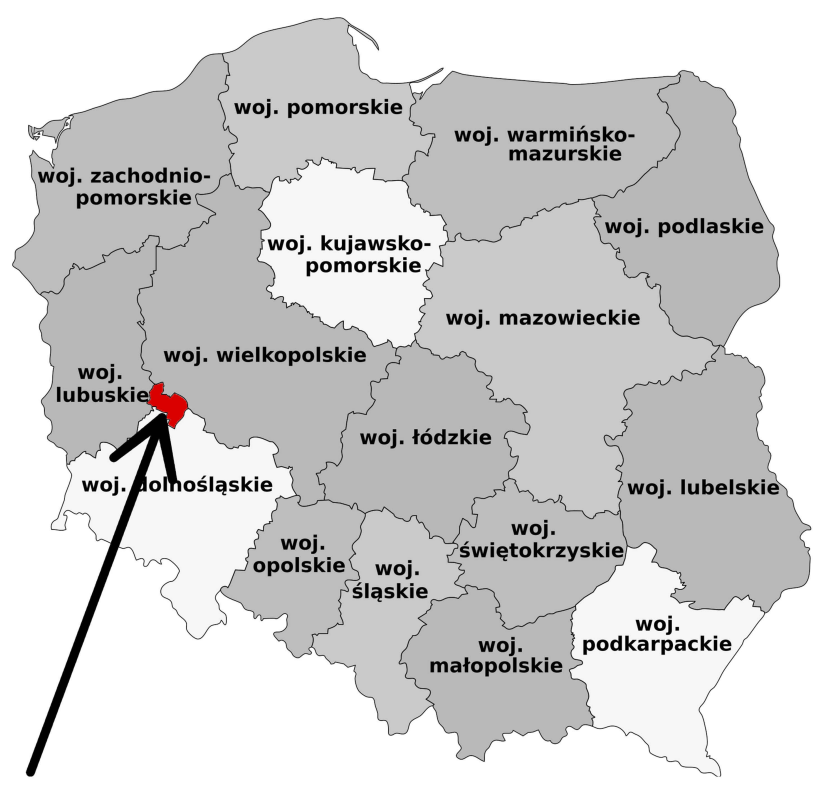

Figure I Wschowa county, Lubuskie province, Poland. diagnosed type 2 diabetes, HDL cholesterol $<40 \mathrm{mg} / \mathrm{dL}$ or treatment for this lipid abnormality, systolic blood pressure $(\mathrm{SBP}) \geq 130 \mathrm{mmHg}$ or diastolic blood pressure (DBP) $\geq 85$ $\mathrm{mmHg}$ or treatment of previous hypertension.

Exclusion criteria included orchitis (present or past), prostate cancer treated with GnRH-analogues, pituitary dysfunction, cryptorchidism (present or past) - a total of 11 men.

Exclusion criteria included orchitis (present or past), prostate cancer treated with GnRH-analogues, pituitary dysfunction, cryptorchidism (present or past) - a total of 11 men.

The baseline characteristics are presented in Table 1.

Total testosterone (TT) serum levels were measured using the ELISA test (DRG International Inc, USA) with a reference range of $2.0-6.9 \mathrm{ng} / \mathrm{mL}$ and a sensitivity of $0.083 \mathrm{ng} / \mathrm{mL}$.

Measurements of free testosterone (FT) plasma concentrations were assessed using DSL-4900 ACTIVE Free Testosterone RIA created by Diagnostic Systems Laboratories, Inc, USA marked with $\mathrm{J}^{125}$ with a reference range of $1.7-62.58 \mathrm{pg} / \mathrm{mL}$ and a sensitivity of $0.18 \mathrm{pg} / \mathrm{mL}$.

DHEA (dehydroepiandrosterone) and its sulfate (DHEA-S) serum levels were evaluated using the ELISA test (Biosource - Belgium) with a reference range of 1.8$12.5 \mathrm{ng} / \mathrm{mL}$ for DHEA and $1.0-4.2 \mu \mathrm{g} / \mathrm{mL}$ for DHEA-S and a sensitivity of $\leq 0.1 \mathrm{ng} / \mathrm{mL}$ for DHEA and $\leq 0.02 \mu \mathrm{g} /$ $\mathrm{mL}$ for DHEAS.

SHBG (sex hormone-binding globulin) serum levels were measured using immunoradiometric assay (IRMA) produced by Beckman Coulter Immunotech, USA/Czech Republic, with a reference range of $20-70 \mathrm{nM} / \mathrm{L}$ and sensitivity of $0.1 \mathrm{nM} / \mathrm{L}$.

The homocysteine plasma level analysis was carried out in column chromatography by means of HPLC/EC (P580, Dionex, Germany) coupled to an electrochemical detector (CoulArray 5600, ESA, USA). The reference values of homocysteine concentrations were determined in the $5-15 \mu \mathrm{M} / \mathrm{L}$ range.

The serum hs-CRP levels were determined using highsensitivity immunoassays with specific antibodies (ELISA) produced by BioCheck (USA). The normal ranges for hs-CRP were below $5 \mathrm{mg} / \mathrm{L}$.

All tests were done twice and an average was taken from both measurements.

We also analyzed calculations of free testosterone (c-FT) and bioavailable testosterone (c-BAT) using a mathematical algorithm proposed by the International Society for the Study of the Aging Male.

Statistical analysis was conducted using Statsoft Statistica 12.1 software. Normal distribution was tested 
Table I Baseline Characteristics Of All Study Participants (Variables Are Shown As Medians With $Q_{1}$ And $Q_{3}$ Values)

\begin{tabular}{|c|c|c|c|}
\hline Variable & $\begin{array}{l}\text { Studied Group (Diagnosed With MS) } \\
N=65\end{array}$ & $\begin{array}{l}\text { Controls (Healthy) } \\
\mathrm{N}=84\end{array}$ & $\mathbf{p}$ \\
\hline Age & $60(50-70)$ & $50(40-60)$ & 0.2992 \\
\hline Brinkmann Index & $300(0-700)$ & $300(0-500)$ & 0.4713 \\
\hline Waist circumference & $106(101-113)$ & $92(86-98.5)$ & $<0.0001$ \\
\hline WHR & 1.01 (1.0-1.03) & I (0.97-I.0I) & 0.0004 \\
\hline BMI & $30(27.7-32.5)$ & $25.15(22.8-28.05)$ & $<0.0001$ \\
\hline Systolic BP & $150(130-160)$ & $140(125-150)$ & 0.0038 \\
\hline Diastolic BP & $90(80-95)$ & $80(80-90)$ & 0.0027 \\
\hline Glucose & $105(98-112)$ & $93(86-96)$ & $<0.0001$ \\
\hline Total cholesterol & $250(217-296)$ & $239.5(208-282.5)$ & 0.1511 \\
\hline Non-HDL cholesterol & 208 (176-249) & $184(148.5-219.5)$ & 0.0025 \\
\hline LDL cholesterol & $172(147-200)$ & 163.5 (132.5-199) & 0.3122 \\
\hline HDL cholesterol & $43(38-50)$ & $55.5(47-68.5)$ & $<0.0001$ \\
\hline Triglycerides & $183(135-229)$ & $100(75.5-124)$ & $<0.0001$ \\
\hline
\end{tabular}

Note: Statistically significant $\mathrm{p}<0.05$ shown in Italics.

with the Lillierfors test. Most data lacked normal distribution and was thus analyzed using non-parametric tests, namely Spearman's rank-order correlation and MannWhitney $U$-tests. The data were presented as medians with 25 th and 75 th quartiles.

To assess factors which may affect MS occurrence, we performed univariate and multivariate logistic regression analysis. In the univariate logistic regression model, the dependent variable was diagnosis of MS and independent factors were age, smoking (yes/no), Brinkmann Index, waist circumference, BMI, systolic BP, diastolic BP, glucose, homocysteine, hs-CRP, total cholesterol, HDL, LDL, nonHDL, triglycerides, FT (free testosterone) - measured, FT (free testosterone) - calculated, bioavailable testosterone, DHEA-S, DHEA, total Testosterone and SHBG.

For multivariate logistic regression, model variables with a p-value $<0.1$ in the aforementioned univariate regression analysis were chosen.
Differences with $\mathrm{p}$-value $<0.05$ were considered statistically significant.

The study was accepted by the local medical ethics committee.

The study was approved by "Komisja Bioetyczna przy Uniwersytecie Medycznym im. Karola Marcinkowskiego w Poznaniu".

Written consent in accordance with Declaration of Helsinki has been obtained from each patient or subject after full explanation of the purpose and nature of all procedures used.

\section{Results}

The values of selected investigated parameters are shown in Table 2.

Groups were analyzed for smoking using the Brinkmann Index (daily cigarettes multiplied by years of smoking), and there was no statistical significance between

Table 2 Selected Investigated Parameters Of All Study Participants (Variables Are Shown As Medians With $Q_{1}$ And $Q_{3}$ Values)

\begin{tabular}{|l|l|l|l|}
\hline Variable & $\begin{array}{l}\text { Studied Group (Diagnosed With MS) } \\
\mathbf{N}=\mathbf{6 5}\end{array}$ & $\begin{array}{l}\text { Controls (Healthy) } \\
\mathbf{N}=\mathbf{8 4}\end{array}$ \\
\hline Homocysteine & $10(8-12.2)$ & $9.1(7.4-11.95)$ & $\mathbf{p}$ \\
hs-CRP & $1.65(0.94-4.56)$ & $1.02(0.44-2.60)$ & $12.57(10.71-15.18)$ \\
Free testosterone - measured & $11.53(9.56-14.43)$ & $1.115(0.6568-1.65)$ & 0.4371 \\
DHEA-S & $0.97(0.55-1.41)$ & $14.01(9.61-17.13)$ & 0.0062 \\
DHEA & $11.58(8.39-15.56)$ & $6.3(5.4-8.25)$ & 0.2556 \\
Total testosterone & $5.2(3.8-6.5)$ & $71.965(54.45-91.56)$ & 0.0350 \\
SHBG & $47.46(35.78-62.83)$ & $80(63.1-105.5)$ & 0.0001 \\
Free testosterone - calculated & $85.2(58.7-108)$ & $1.88(1.48-2.495)$ & 0.9969 \\
BAT & $2.01(1.46-2.66)$ & 0.7305 \\
\hline
\end{tabular}

Note: Statistically significant $\mathrm{p}<0.05$ shown in italics. 
the control and study groups regarding exposure to smoking. The groups did not differ statistically significant in baseline characteristics with reference to total and LDL cholesterol as well as to homocysteine serum levels. Likewise, there was no statistical significance for the difference in plasma levels of FT and parameters calculated: c-FT, c-BAT.

In contrast, statistical significance was achieved for DHEA, SHBG, hs-CRP and total testosterone plasma concentrations.

Total testosterone plasma levels showed positive associations with HDL cholesterol ( $\mathrm{p}=0.0256, \mathrm{R}=0.182)$, and negative ones with waist circumference $(p=0.0000003, R=$ $-0.4), \operatorname{WHR}(\mathrm{p}=0.000046, \mathrm{R}=-0.327)$, BMI $(\mathrm{p}=0.000025$, $\mathrm{R}=-0.338)$, fasting glucose level $(\mathrm{p}=0.0138, \mathrm{R}=-0.21)$ and triglycerides $(\mathrm{p}=0.0388, \mathrm{R}=-0.17)$. No association was shown with age in our study, neither in both groups together nor in either of the groups separately.

SHBG serum levels demonstrated positive association with total testosterone $(\mathrm{p}<0.0000001, \mathrm{R}=0.564)$, HDL cholesterol $(\mathrm{p}=0.000533, \mathrm{R}=0.28)$ and age $(\mathrm{p}=0.0105, \mathrm{R}=$ $0.209)$ while negative with waist circumference $(p=0.000002$, $\mathrm{R}=-0.375)$, WHR $(\mathrm{p}=0.0013, \mathrm{R}=-0.261)$, BMI $(\mathrm{p}=$ $0.000003, \mathrm{R}=-0.372)$, TGA $(\mathrm{p}=0.000004, \mathrm{R}=-0.366)$ and fasting glucose level $(\mathrm{p}=0.000251, \mathrm{R}=-0.308)$.

Further analysis, namely Kruskal-Wallis ANOVA, shows the difference in SHBG between patients with MS in different age groups $(p=0.0415)$, but does not show any statistical difference among the controls in different age groups. Close analysis of each age group with the MannWhitney $U$-test shows a statistical difference in SHBG plasma levels among patients with metabolic syndrome aged 40 and $60(\mathrm{p}=0.0328)$, as well as aged 50 and $60(\mathrm{p}$ $=0.04$ ) years, showing, with statistical significance, lower levels of SHBG in younger groups than in older groups.

Changes in the concentrations of SHBG, DHEA and total testosterone in particular age groups are shown in Figure 2.

DHEA plasma levels showed a negative association with age $(\mathrm{p}=0.0003, \mathrm{R}=-0.292)$, systolic blood pressure $(p=0.032, R=-0.176)$ and metabolic syndrome $(p=0.034$, $\mathrm{R}=-0.174)$. DHEA-S serum concentrations showed a negative association with age $(\mathrm{p}=<0.0001, \mathrm{R}=-0.495)$ and systolic blood pressure $(p=0.0009, R=-0.269)$, but showed no association with metabolic syndrome $(\mathrm{p}=0.2562)$.

Serum hs-CRP levels correlated positively with age $(\mathrm{p}=$ $0.0403, \mathrm{R}=0.168)$, waist circumference $(\mathrm{p}=0.000062, \mathrm{R}=$ 0.322), WHR $(\mathrm{p}=0.009521, \mathrm{R}=0.212), \mathrm{BMI}(\mathrm{p}=0.00106, \mathrm{R}$

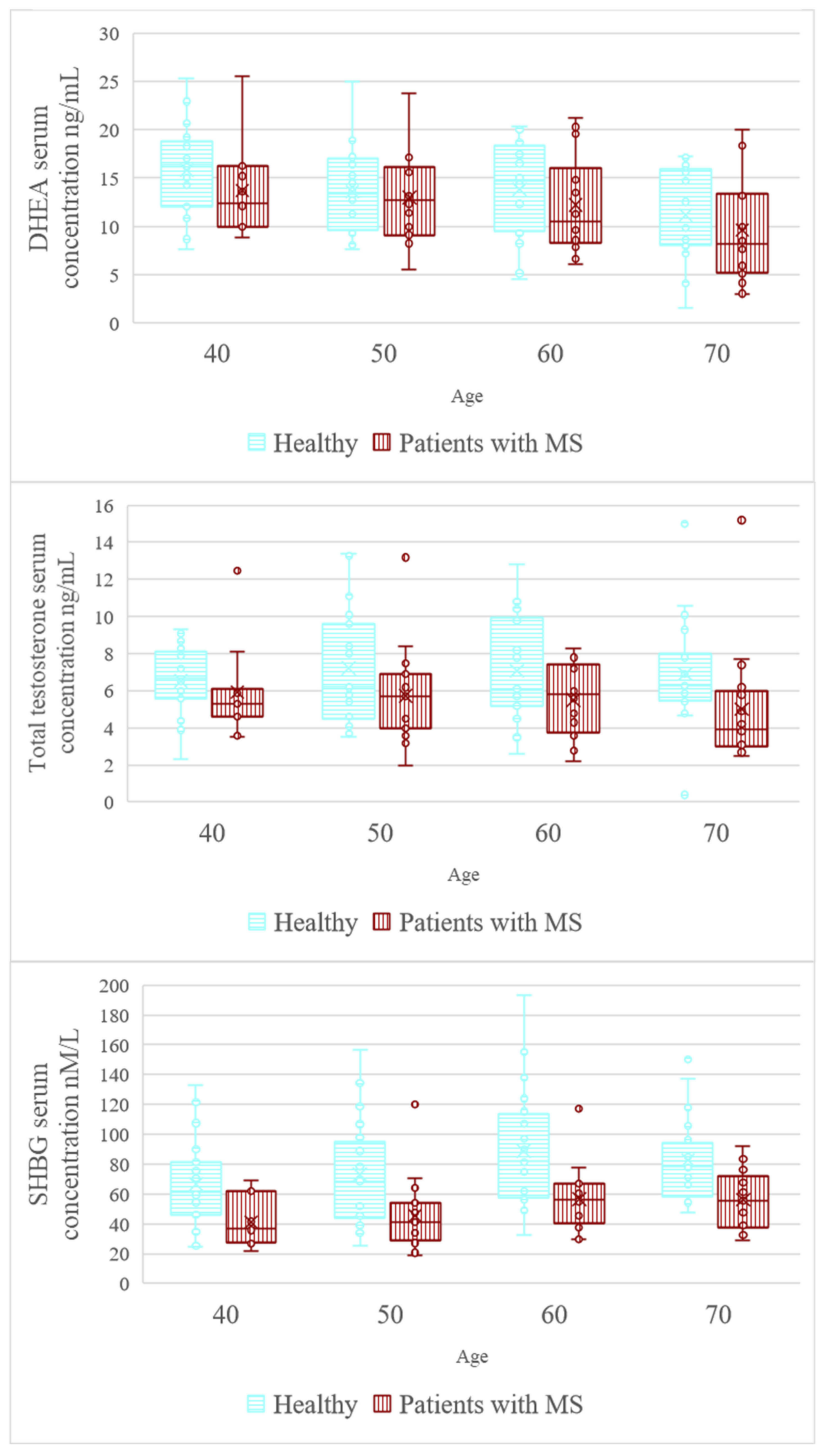

Figure 2 Serum concentrations of selected parameters in age group among patients with metabolic syndrome.

$=0.266)$, systolic blood pressure $(\mathrm{p}=0.02, \mathrm{R}=0.190)$, diastolic blood pressure $(\mathrm{p}=0.02, \mathrm{R}=0.191)$, metabolic syndrome $(p=0.006, R=0.225)$ and negatively with SHBG $(\mathrm{p}=0.0166, \mathrm{R}=-0.196)$ and HDL $(\mathrm{p}=0.00915, \mathrm{R}=-0.213)$.

In the study, positive associations were found between age and BMI $(\mathrm{p}=0.01 \mathrm{R}=0.2)$ as well as between age and waist circumference (among healthy $\mathrm{p}=0.047 \mathrm{R}=$ 0.217 among patients with MS $\mathrm{p}=0.0046, \mathrm{R}=0.35$ and both groups together $\mathrm{p}=0.001 \mathrm{R}=0.266$ ).

Comparison of the Spearman's rank correlation coefficient of particular MS diagnostic criteria and SHBG with MS prevalence is shown in Table 3.

Furthermore, all of the abovementioned parameters differ with statistical significance in each age group, 
Table 3 Comparison Of Association Between Particular MS Elements Plus SHBG And MS Prevalence (Spearman's Rank Correlation Coefficient $\left(r_{s}\right)$ And P-Value Are Presented)

\begin{tabular}{|l|l|l|}
\hline & $\boldsymbol{r}_{\mathbf{s}}$ & $\mathbf{p}$ \\
\hline Waist circumference & 0.635 & $<0.000 \mathrm{I}$ \\
Fasting plasma glucose & 0.621 & $<0.000 \mathrm{I}$ \\
Triglycerides & 0.602 & $<0.000 \mathrm{I}$ \\
Cholesterol HDL & -0.464 & $<0.000 \mathrm{I}$ \\
SHBG & -0.435 & $<0.000 \mathrm{I}$ \\
Diastolic blood pressure & 0.247 & 0.0024 \\
Systolic blood pressure & 0.238 & 0.0035 \\
\hline
\end{tabular}

Note: Statistically significant $p<0.05$ shown in italics.

except for blood pressure. Systolic and diastolic blood pressure only differ statistically in the eldest group.

Univariate and multivariate regression models are presented in Table 4 and Figure 3.

\section{Discussion}

Andropause is a condition associated with a decrease in testosterone. This decrease can lead to many problems, namely changes in mood, sex drive, and attitude to life, but can also lead to an increased risk of a multitude of health complications, like osteopenia and osteoporosis or heart disease.

The criteria for metabolic syndrome differ depending on the source, but in 2009 , the criteria were unified, ${ }^{6}$ requiring 3 out of 5 criteria to be met, with increased waist circumference being one of them, but not the mandatory one. We decided to choose International Diabetes Federation criteria (established in 2005), which differ by requiring central obesity as a major criterion plus two out of four other criteria, as we believe in the importance of central obesity in metabolic syndrome, affecting cytokines and whole inflammatory homeostasis.

SHBG increases with age at a rate of roughly $1.6 \%$ / year, while total testosterone sees a decrease of roughly 1.6\%/year. ${ }^{7}$ DHEA and DHEA-S showed a sharp decline of $2-3 \% /$ year. $^{8}$ Those results are generally in line with our research, namely an increase in SHBG and a decrease in DHEA and DHEA-S with age.

When it comes to total testosterone decline, the results are conflicting. There are those showing a decline, ${ }^{9-11}$ as well as those showing no change, ${ }^{12,13}$ as was the case in our study, especially among exceptionally healthy elderly males. ${ }^{14}$ Those conflicting results, together with differences between cross-sectional and longitudinal results and disappearance of changes in the decline of testosterone when analyzed for a lack of "apparent health" in this particular study of 1709 men, suggest that incidental poor health has a major impact on androgen decline. ${ }^{7} \mathrm{We}$ imply that an increase in weight with age, as shown in our study, and incidents of poor health cause changes in TT, not age alone. Findings suggesting the negative influence of fat and obesity on TT and SHBG are found in many publications. ${ }^{2,13,15-17}$ Our suggestion is that the increase of SHBG with age is insignificant in terms of its change related to MS and obesity among patients both young and old, and is thus a good early marker of metabolic dysregulation affecting androgen status in patients with MS.

In our results, both BMI and waist circumference increase with age. In the case of waist circumference, the increase is present for controls, the study group and both together, but the Spearman's rank correlation coefficient for a waist circumference increase with age is higher in patients with metabolic syndrome. This suggests that metabolic syndrome is associated with even higher agerelated central adiposity.

There are a number of publications that link metabolic syndrome, insulin resistance and low TT, as well as adrenal C12 steroids and decreased SHBG concentrations. ${ }^{18,19}$ These findings correlate with our own. Findings generally link a decrease in androgens with age, namely testosterone, as an underlying cause for MS in elderly men. ${ }^{20}$

We found positive associations between testosterone and HDL cholesterol and negative with waist circumference, fasting glucose level, WHR, BMI and TGA, which are comparable to the results of another publication. ${ }^{21}$

In our study, we show that free indexes (both measured and calculated) are not good methods for assessment of decrease in testosterone as a consequence of metabolic syndrome. In our analysis, free-T showed no association with age nor MS neither in both groups together nor in healthy and MS groups separately, suggesting its low diagnostic usefulness. This may be caused by the imperfection of free-testosterone assays and interference of the age- and weight-dependent changes in plasma SHBG concentrations.

In terms of calculated bioavailable testosterone and free testosterone, they both show no differences between healthy and MS patients (Table 1), which is also found in another study. ${ }^{17}$ There is also no association of calculated BAT and FT with MS, but both have a negative and statistically significant association with age. This association can be attributed to a general increase in SHBG with 


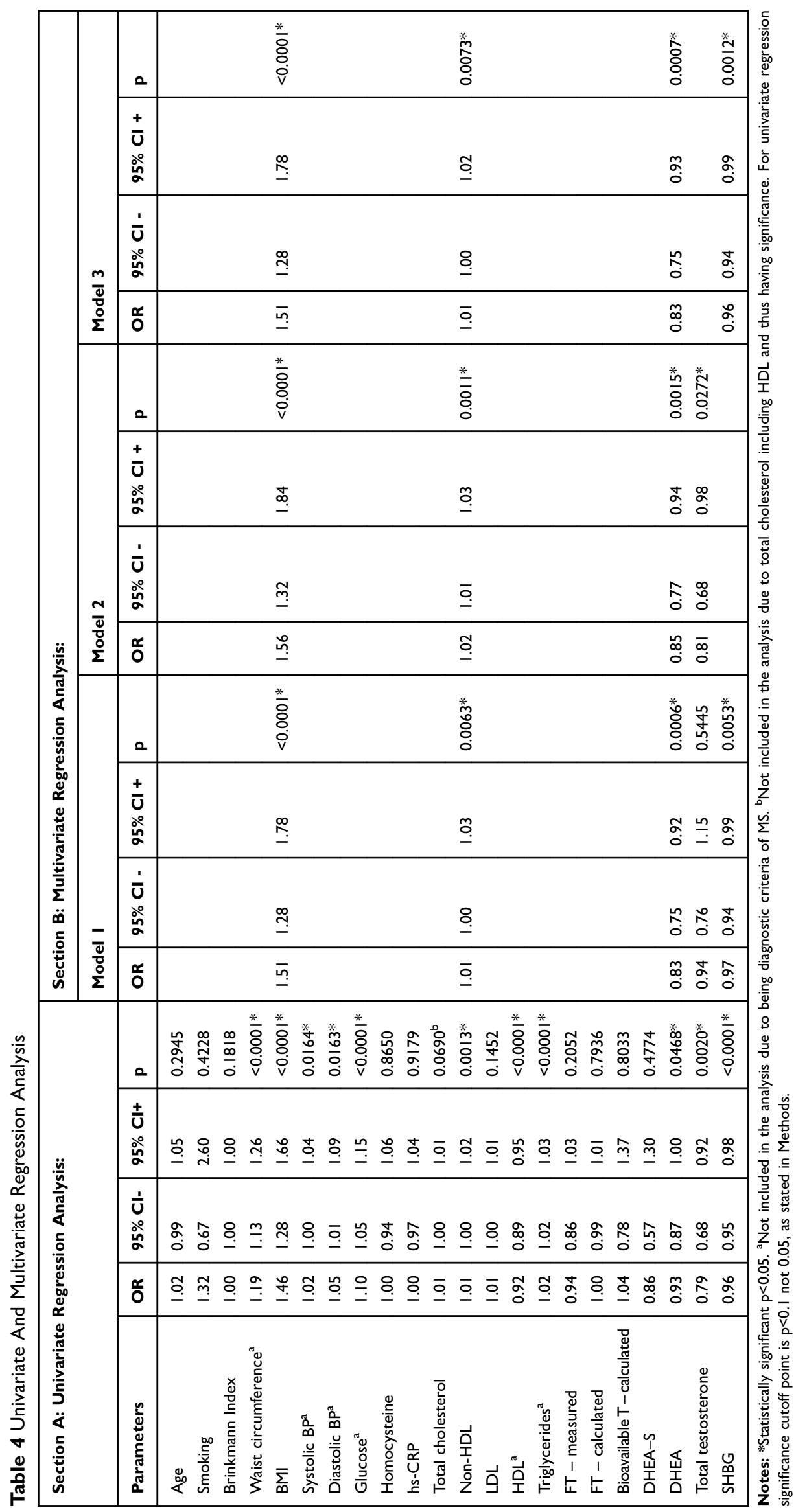




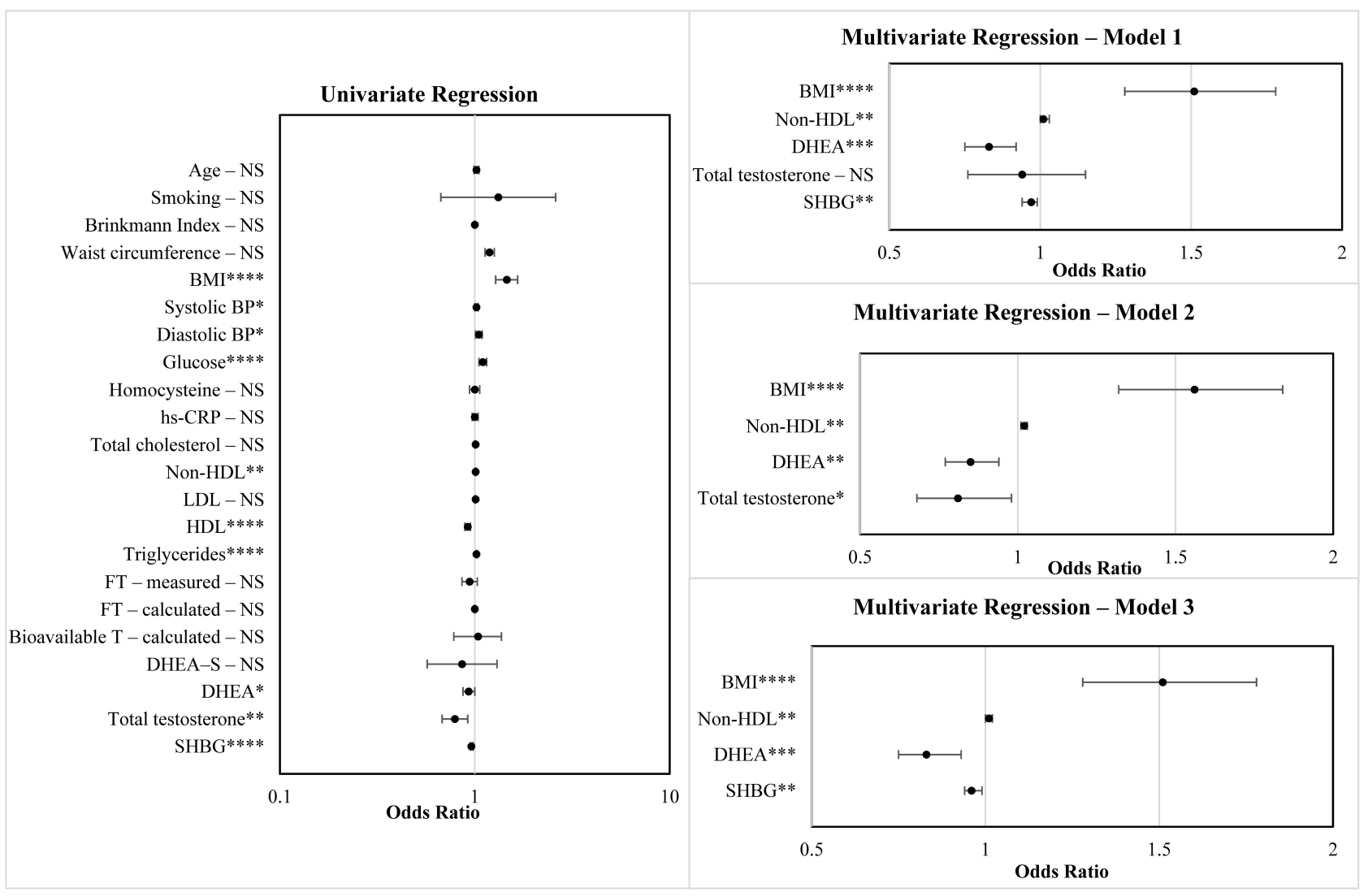

Figure 3 Univariate regression and three models for multivariate regression - forest plots.

Notes: NS - non-significant, ${ }^{*} \mathrm{p}<0.05$, ${ }^{* *} \mathrm{p}<0.01$, ${ }^{* * *} \mathrm{p}<0.001$, $* * * * \mathrm{p}<0.000$ I.

Abbreviations: BMI, body mass index; BP, blood pressure; CRP, c-reactive protein; non-HDL, total cholesterol minus HDL; LDL, low-density lipoprotein; HDL, high-density lipoprotein; FT, free testosterone; DHEA, dehydroepiandrosterone; SHBG, sex hormone-binding globulin.

age, thus falsely showing a negative association between c-FT and c-BAT with age due to the way it is calculated. Thus, in our opinion, the parameters calculated can give false information to clinicians about the androgenic status of patients and should not be used.

There is still a great deal of inconsistency in the results showing the impact of DHEA and DHEA-S plasma concentrations on the development of MS and cardiovascular disease, as well as possible causation and underlying mechanisms. DHEA and DHEA-S focused review article suggests that DHEA and DHEA-S levels decrease because of glucose intolerance and insulin resistance increasing with age. ${ }^{22}$

It is especially important to note that the role of changing of levels of DHEA-S in the development of MS is not evident. Some publications show no association between DHEA-S and MS, which is consistent with our results. $^{20,23-25}$ However, Chinese authors show DHEA-S elevation to be a risk factor for the development of metabolic syndrome in elderly men. ${ }^{26}$ The authors suggest that one of the plausible mechanisms is DHEA conversion to testosterone, explaining both elevated DHEA and a decrease in testosterone. Insulin also further increases the production of DHEA-S, as shown in an in-vitro study, but the authors suggest that the effects are not uniform between subjects. ${ }^{27}$ However, other articles completely debunk those claims, proving the complete opposite by stating that insulin has no impact on DHEA or DHEA-S production and regulation, ${ }^{28,29}$ or even by showing that the decrease in insulinemia through benfluorex treatment raises DHEA and DHEA-S. ${ }^{30}$ There is also evidence that replacement of DHEA in aging humans can positively affect insulin resistance, ${ }^{31}$ while another publication showed no effect except an increase of DHEA-S. ${ }^{32}$ The only thing all of those articles agree on is that further research warranting a bigger study group is definitely needed, preferably in a long-term prospective study.

Studies also find that high insulin levels increase the metabolic clearance of DHEA and DHEA-S, thus explaining its serum decrease in $\mathrm{MS}^{33,34}$ The unknown is 
whether DHEA is only decreased because of hyperinsulinemia in MS or whether it actually plays some underlying cause in the patomechanisms of MS.

DHEA increases the expression of glucose transporters within adipose tissue and increases oxidation of lipids and overall glucose usage. DHEA shows an insulin-like effect, thus decreasing insulin concentrations. What is also worth mentioning is the positive effect of both $\mathrm{T}$ and DHEA on visceral adipose tissue, namely decreasing visceral fat accumulation in men and visceral fat oxidation. ${ }^{35,36}$ Recent publications on the topic suggest that both DHEA and its sulfate might exert an effect by plasma membrane receptors, neuroreceptors, steroid receptors and being metabolized into more potent steroids. ${ }^{37}$

Although the $p$-value of difference in plasma levels of DHEA-S between MS group and controls in our study was not of statistical significance, it was close to it, warranting a bigger studied group and further research, especially after considering conflicting results from previous studies.

Another avenue worth exploration and consideration are diseases that affect androgen metabolism. Some of them might be greatly underdiagnosed, like Kallmann syndrome, Klinefelter syndrome and rare forms of congenital adrenal hyperplasia. Patients with Klinefelter syndrome have a higher risk of cardiovascular disease and develop T2DM, MS and insulin resistance more often than the general population. ${ }^{38}$

In case of Kallmann syndrome, the risk for is also worth considering, in one study 9 out of 23 participants suffered from obesity. ${ }^{39}$ There is a possibility that a part of the patients suffering from both hypogonadism and MS actually suffer from some underlying, undiagnosed condition. This implies that clinicians dealing with patients suffering from MS and hypogonadism should always have those rarer diseases in mind.

Low SHBG is associated with hyperinsulinemia and insulin resistance, showing the negative impact of high insulin on hepatic SHBG production. ${ }^{40-42}$ This indicates that men with isolated hyperinsulinemia or insulin resistance may have hypogonadism and/or be on the path to metabolic syndrome. This would be suggestive of SHBG being a good early marker for metabolic dysregulation and potentially hypogonadism. The same study on in-vitro cell line found an inhibitory effect of high levels of prolactin on hepatic production of SHBG.

On the other hand, low concentrations of SHBG affect the ectopic location of adipose tissue (mainly in the liver, skeletal muscle and pancreas). Recently, it has been shown that a reduction in SHBG concentration in young men is a predictor of nonalcoholic fatty liver disease development in middle age. ${ }^{43}$

In one particular study, SHBG presented with a strong and inverse association not only with MS, but also its components alone, namely waist circumference, HDL-C and triglycerides, and the authors suggest that its association with MS is stronger than testosterone, which is in accordance with our results. They also took into consideration the negative impact of insulin on levels of SHBG, and even after taking it as confounder in analysis, the relation between SHBG and MS remained statistically significant, thus further increasing its value as a predictor of $\mathrm{MS}^{24}$ Comparable results of a negative association between SHBG and metabolic syndrome were also found among monozygotic twins in another study. ${ }^{44}$ It is suggested in some research papers that SHBG might not be only a transport protein, but also interact with tissue-specific membrane receptors in different tissues, namely breast, prostate, testes, liver and possibly muscles. ${ }^{45,46}$

One publication shows an increase in SHBG, testosterone and HDL-C, along with a decrease in insulin and leptin levels following a 10-week regimen of very-lowenergy diet in obese men losing weight. ${ }^{47}$ This further shows a link between the aforementioned serum markers and metabolic syndrome, showing an improvement in testosterone, SHBG and HDL-C, and a decrease in factors of MS, namely insulin levels, leptin and weight. The significant reduction in SHBG levels is worth noting in the youngest men suffering from MS, whereas the levels of testosterone, and especially DHEA, were not much different from each other. Our analysis of differences of SHBG among patients with metabolic syndrome in different age groups showed differences between younger and older patients, which is not present in the healthy controls. This shows that the decrease of SHBG is most pronounced in younger patients (namely mostly 40 and 50 years old), suggesting the early diagnostic role of SHBG.

The strength of association and the significance of SHBG plasma concentrations with MS diagnosis is at least the same or higher (blood pressure) as the associated strength of its particular MS diagnostic elements (Table 2)

In our study, CRP shows a positive association with age, which was also found in a previous study. ${ }^{48}$ It also displays a positive association with many components or 
consequences of MS and negative with SHBG and HDL, which suggests that inflammation plays an important role in the development of $\mathrm{MS}^{49}$ and is connected to insulin resistance. ${ }^{50-52}$ SHBG also affects inflammatory pathways by interacting with lymphocytes via membrane receptors. ${ }^{53}$ CRP shows no direct association with androgens, both gonadal and adrenal, implying that SHBG changes might happen prior to changes in androgens, suggesting even more the important role of early SHBG imbalance in MS. Our current and earlier research suggests that the consequence of chronic inflammation in patients with metabolic syndrome might be more complicated, affecting hormones and their carrier proteins as well. ${ }^{54}$

The evidence from an older study on HepG2 cell production of SHBG being inhibited by insulin was questioned, suggesting that the action of insulin is not specific and instead that TNF- $\alpha$ is the main factor by which SHBG is downregulated in obesity, ${ }^{55}$ further supporting the bigger impact of the inflammatory process. This warrants further research into the avenue of inflammation in MS, considering that treatment with antiTNF $\alpha$ in patients with autoimmune diseases has beneficial effects on insulin sensitivity. ${ }^{56}$ A second article debunking the aspect of insulin action on downregulation of hepatic production SHBG is actually associated with the consumption of sugars and its metabolic consequences, rather than insulin itself. ${ }^{57}$

In our regression analysis, we first conducted an univariate analysis to find good variables for multivariate analysis. We did not include variables associated with MS, namely its diagnostic criteria and total cholesterol, because it includes HDL and thus we decided to include non-HDL cholesterol. We decided to present 3 models. The first one shows all 5 variables fitting the criteria for inclusion in multivariate analysis. The second one without SHBG and the third one without total testosterone. The reason for the two models with exclusion of either SHBG and TT was their strong association and through these models we wanted to show which one has a bigger impact on MS. Our results show that changes in TT associated with MS are linked to underlying changes in SHBG and indirectly to TT. Based on the results in model 2 vs 1 , we show that TT only is significant as long as SHBG is kept out of the analysis, while SHBG results are not affected greatly by TT (model 1 vs 3 ). This implies that the more important variable in MS prediction is SHBG, TT changes are secondary to changes in SHBG and in line with previous research on the subject both in a cross-sectional analysis of 3294 men and in a longitudinal analysis of 618 men. ${ }^{58}$ Furthermore, this would imply that people with high SHBG are less inclined to suffer from MS and diabetes throughout their life, suggesting genetic predisposition to different levels of SHBG having an impact on the chance of developing MS or T2DM throughout life, ${ }^{59,60}$ while another study debunks previous claims. ${ }^{61}$ The small amount of research on the genetic predisposition of SHBG regulation and expression warrants further research into the topic.

People with low SHBG are at higher risk of MS (shown in the results of our multivariate analysis model 1 and 3 ). This relates to both men and women, according to many studies, ${ }^{2,4,15,16,58}$ as well as meta-analysis consisting of 2500 men and 4765 women. $^{62}$

Our study is cross-sectional research. The role of SHBG in the early diagnostics of metabolic syndrome is greatly undervalued. For this reason, we began a follow-up prospective study of individual age groups to confirm the diagnostic value of SHBG concentrations for early MS diagnosis in young men.

\section{Funding}

This research did not receive any specific grant from any funding agency in the public, commercial or not-for-profit sector.

\section{Disclosure}

The authors report no conflicts of interest in this work.

\section{References}

1. Basaria S, Muller DC, Carducci MA, Egan J, Dobs AS Hyperglycemia and insulin resistance in men with prostate carcinoma who receive androgen-deprivation therapy. Cancer. 2006;106(3):581588. doi:10.1002/cncr.21642

2. Hajamor S, Després J-P, Couillard C, et al. Relationship between sex hormone-binding globulin levels and features of the metabolic syndrome. Metabolism. 2003;52(6):724-730. doi:10.1016/s0026-0495(03) 00066-0

3. Laaksonen DE, Niskanen L, Punnonen K, et al. Testosterone and sex hormone-binding globulin predict the metabolic syndrome and diabetes in middle-aged men. Diabetes Care. 2004;27(5):1036-1041. doi:10.2337/diacare.27.5.1036

4. Kupelian V, Page ST, Araujo AB, Travison TG, Bremner WJ, McKinlay JB. Low sex hormone-binding globulin, total testosterone, and symptomatic androgen deficiency are associated with development of the metabolic syndrome in nonobese men. J Clin Endocrinol Metab. 2006;91(3):843-850. doi:10.1210/jc.2005-1326

5. Hak AE, Witteman JCM, de Jong FH, Geerlings MI, Hofman A, Pols HAP. Low levels of endogenous androgens increase the risk of atherosclerosis in elderly men: the Rotterdam Study. J Clin Endocrinol Metab. 2002;87(8):3632-3639. doi:10.1210/jcem.87.8.8762 
6. Alberti KGMM, Eckel RH, Grundy SM, et al. Harmonizing the metabolic syndrome: a joint interim statement of the International Diabetes Federation Task Force on Epidemiology and Prevention; National Heart, Lung, and Blood Institute; American Heart Association; World Heart Federation; International Atherosclerosis Society; and International Association for the Study of Obesity. Circulation. 2009;120(16):16401645. doi:10.1161/CIRCULATIONAHA.109.192644

7. Feldman HA, Longcope C, Derby CA, et al. Age trends in the level of serum testosterone and other hormones in middle-aged men: longitudinal results from the Massachusetts male aging study. J Clin Endocrinol Metab. 2002;87(2):589-598. doi:10.1210/jcem.87.2.8201

8. Tannenbaum C, Barrett-Connor E, Laughlin GA, Platt RW. A longitudinal study of dehydroepiandrosterone sulphate (DHEAS) change in older men and women: the Rancho Bernardo Study. Eur J Endocrinol. 2004;151(6):717-725. doi:10.1530/eje.0.1510717

9. Vermeulen A, Rubens R, Verdonck L. Testosterone secretion and metabolism in male senescence. J Clin Endocrinol Metab. 1972;34 (4):730-735. doi:10.1210/jcem-34-4-730

10. Morley JE, Kaiser FE, Perry HM, et al. Longitudinal changes in testosterone, luteinizing hormone, and follicle-stimulating hormone in healthy older men. Metabolism. 1997;46(4):410-413. doi:10.1016/ s0026-0495(97)90057-3

11. Harman SM, Metter EJ, Tobin JD, Pearson J, Blackman MR; Baltimore Longitudinal Study of Aging. Longitudinal effects of aging on serum total and free testosterone levels in healthy men. J Clin Endocrinol Metab. 2001;86(2):724-731. doi:10.1210/jcem.86.2.7219

12. Sparrow D, Bosse R, Rowe JW. The influence of age, alcohol consumption, and body build on gonadal function in men. J Clin Endocrinol Metab. 1980;51(3):508-512. doi:10.1210/jcem-51-3-508

13. van Den Beld AW, de Jong FH, Grobbee DE, Pols HA, Lamberts SW. Measures of bioavailable serum testosterone and estradiol and their relationships with muscle strength, bone density, and body composition in elderly men. J Clin Endocrinol Metab. 2000;85(9):32763282. doi:10.1210/jcem.85.9.6825

14. Harman SM, Tsitouras PD. Reproductive hormones in aging men. I. Measurement of sex steroids, basal luteinizing hormone, and Leydig cell response to human chorionic gonadotropin. J Clin Endocrinol Metab. 1980;51(1):35-40. doi:10.1210/jcem-51-1-35

15. Li C, Ford ES, Li B, Giles WH, Liu S. Association of testosterone and sex hormone-binding globulin with metabolic syndrome and insulin resistance in men. Diabetes Care. 2010. doi:10.2337/dc09-1788

16. de Sá EQC, de Sá FCF, Oliveira KC, Feres F, Verreschi ITN. Association between sex hormone-binding globulin (SHBG) and metabolic syndrome among men. Sao Paulo Med J Rev Paul Med. 2014;132(2):111-115.

17. Cooper LA, Page ST, Amory JK, Anawalt BD, Matsumoto AM. The association of obesity with sex hormone-binding globulin is stronger than the association with ageing-implications for the interpretation of total testosterone measurements. Clin Endocrinol (Oxf). 2015;83 (6):828-833. doi:10.1111/cen.12768

18. Seidell JC, Björntorp P, Sjöström L, Kvist H, Sannerstedt R. Visceral fat accumulation in men is positively associated with insulin, glucose, and C-peptide levels, but negatively with testosterone levels. Metabolism. 1990;39(9):897-901. doi:10.1016/0026-0495(90)90297-p

19. Tchernof A, Labrie F, Bélanger A, Després JP. Obesity and metabolic complications: contribution of dehydroepiandrosterone and other steroid hormones. J Endocrinol. 1996;150(Suppl):S155-164.

20. Haring R, Völzke H, Felix SB, et al. Prediction of metabolic syndrome by low serum testosterone levels in men: results from the study of health in Pomerania. Diabetes. 2009;58(9):2027-2031. doi:10.2337/db09-0031

21. Mohammed M, AL-Habori M, Abdullateef A, Saif-Ali R. Impact of metabolic syndrome factors on testosterone and SHBG in type 2 diabetes mellitus and metabolic syndrome. J Diabetes Res. 2018. doi: $10.1155 / 2018 / 4926789$
22. Kroboth PD, Salek FS, Pittenger AL, Fabian TJ, Frye RF. DHEA and DHEA-S: a review. J Clin Pharmacol. 1999;39(4):327-348. doi:10.1177/00912709922007903

23. Blouin K, Després J-P, Couillard C, et al. Contribution of age and declining androgen levels to features of the metabolic syndrome in men. Metabolism. 2005;54(8):1034-1040. doi:10.1016/j.metabol.2005.03.006

24. Maggio M, Lauretani F, Ceda GP, et al. Association between hormones and metabolic syndrome in older Italian men. $J$ Am Geriatr Soc. 2006;54(12):1832-1838. doi:10.1111/j.1532-5415.2006.00963.x

25. Rodriguez A, Muller DC, Metter EJ, et al. Aging, androgens, and the metabolic syndrome in a longitudinal study of aging. $J$ Clin Endocrinol Metab. 2007;92(9):3568-3572. doi:10.1210/jc.2006-2764

26. Chen YC, Chang HH, Wen CJ, et al. Elevated serum dehydroepiandrosterone sulphate level correlates with increased risk for metabolic syndrome in the elderly men. Eur J Clin Invest. 2010;40(3):220-225. doi:10.1111/j.1365-2362.2009.02248.x

27. Hines GA, Smith ER, Azziz R. Influence of insulin and testosterone on adrenocortical steroidogenesis in vitro: preliminary studies. Fertil Steril. 2001;76(4):730-735. doi:10.1016/S0015-0282(01)02014-3

28. Vermeulen A, Kaufman JM, Giagulli VA. Influence of some biological indexes on sex hormone-binding globulin and androgen levels in aging or obese males. J Clin Endocrinol Metab. 1996;81(5):18211826. doi:10.1210/jcem.81.5.8626841

29. Pasquali R, Macor C, Vicennati V, et al. Effects of acute hyperinsulinemia on testosterone serum concentrations in adult obese and normal-weight men. Metabolism. 1997;46(5):526-529. doi:10.1016/ s0026-0495(97)90189-x

30. Nestler JE, Beer NA, Jakubowicz DJ, Colombo C, Beer RM. Effects of insulin reduction with benfluorex on serum dehydroepiandrosterone (DHEA), DHEA sulfate, and blood pressure in hypertensive middle-aged and elderly men. J Clin Endocrinol Metab. 1995;80 (2):700-706. doi:10.1210/jcem.80.2.7852539

31. Weiss EP, Villareal DT, Fontana L, Han D-H, Holloszy JO. Dehydroepiandrosterone (DHEA) replacement decreases insulin resistance and lowers inflammatory cytokines in aging humans. Aging. 2011;3(5):533-542. doi:10.18632/aging.100327

32. Talaei A, Amini M, Siavash M, Zare M. The effect of dehydroepiandrosterone on insulin resistance in patients with impaired glucose tolerance. Horm Athens Greece. 2010;9(4):326-331.

33. Nestler JE, Kahwash Z. Sex-specific action of insulin to acutely increase the metabolic clearance rate of dehydroepiandrosterone in humans. $J$ Clin Invest. 1994;94(4):1484-1489. doi:10.1172/JCI117487

34. Lavallée B, Provost PR, Kahwash Z, Nestler JE, Bélanger A. Effect of insulin on serum levels of dehydroepiandrosterone metabolites in men. Clin Endocrinol (Oxf). 1997;46(1):93-100. doi:10.1046/j.13652265.1997.d01-1736.x

35. De Pergola G. The adipose tissue metabolism: role of testosterone and dehydroepiandrosterone. Int J Obes Relat Metab Disord J Int Assoc Study Obes. 2000;24 Suppl 2:S59-S63.

36. Hernández-Morante JJ, Pérez-de-Heredia F, Luján JA, Zamora S, Garaulet M. Role of DHEA-S on body fat distribution: gender- and depot-specific stimulation of adipose tissue lipolysis. Steroids. 2008;73(2):209-215. doi:10.1016/j.steroids.2007.10.005

37. Clark BJ, Prough RA, Klinge CM. Mechanisms of action of dehydroepiandrosterone. Vitam Horm. 2018;108:29-73. doi:10.1016/bs. vh.2018.02.003

38. Salzano A, D'Assante R, Heaney LM, et al. Klinefelter syndrome, insulin resistance, metabolic syndrome, and diabetes: review of literature and clinical perspectives. Endocrine. 2018;61(2):194-203. doi:10.1007/s12020-018-1584-6

39. Lieblich JM, Rogol AD, White BJ, Rosen SW. Syndrome of anosmia with hypogonadotropic hypogonadism (kallmann syndrome): clinical and laboratory studies in 23 cases. Am J Med. 1982;73(4):506-519. doi:10.1016/0002-9343(82)90329-1 
40. Plymate SR, Matej LA, Jones RE, Friedl KE. Inhibition of sex hormone-binding globulin production in the human hepatoma (Hep G2) cell line by insulin and prolactin. J Clin Endocrinol Metab. 1988;67(3):460-464. doi:10.1210/jcem-67-3-460

41. Pasquali R, Casimirri F, De Iasio R, et al. Insulin regulates testosterone and sex hormone-binding globulin concentrations in adult normal weight and obese men. J Clin Endocrinol Metab. 1995;80(2):654 658. doi:10.1210/jcem.80.2.7852532

42. Hautanen A. Synthesis and regulation of sex hormone-binding globulin in obesity. Int J Obes Relat Metab Disord J Int Assoc Study Obes. 2000;24 Suppl 2:S64-S70. doi:10.1038/sj.ijo.0801281

43. Sarkar M, VanWagner LB, Terry JG, et al. Sex hormone-binding globulin levels in young men are associated with nonalcoholic fatty liver disease in midlife. Am J Gastroenterol. 2019. doi:10.14309/ajg.0000000000000138

44. Moon H, Choi I, Kim S, et al. Cross-sectional association between testosterone, sex hormone-binding globulin and metabolic syndrome: the Healthy Twin Study. Clin Endocrinol (Oxf). 2017;87(5):523-531. doi: $10.1111 /$ cen. 13390

45. Heinlein CA, Chang C. The roles of androgen receptors and androgenbinding proteins in nongenomic androgen actions. Mol Endocrinol Baltim Md. 2002;16(10):2181-2187. doi:10.1210/me.2002-0070

46. Kahn SM, Hryb DJ, Nakhla AM, Romas NA, Rosner W. Sex hormone-binding globulin is synthesized in target cells. J Endocrinol. 2002;175(1):113-120. doi:10.1677/joe.0.1750113

47. Kaukua J, Pekkarinen T, Sane T, Mustajoki P. Sex hormones and sexual function in obese men losing weight. Obes Res. 2003;11 (6):689-694. doi:10.1038/oby.2003.98

48. Hutchinson WL, Koenig W, Fröhlich M, Sund M, Lowe GDO, Pepys MB. Immunoradiometric assay of circulating C-reactive protein: age-related values in the adult general population. Clin Chem. 2000;46(7):934-938.

49. Eckel RH, Grundy SM, Zimmet PZ. The metabolic syndrome. Lancet. 2005;365(9468):1415-1428. doi:10.1016/S0140-6736(05)66378-7

50. Maury E, Brichard SM. Adipokine dysregulation, adipose tissue inflammation and metabolic syndrome. Mol Cell Endocrinol. 2010;314(1):1-16. doi:10.1016/j.mce.2009.07.031

51. Esser N, Legrand-Poels S, Piette J, Scheen AJ, Paquot N. Inflammation as a link between obesity, metabolic syndrome and type 2 diabetes. Diabetes Res Clin Pract. 2014;105(2):141-150. doi:10.1016/j.diabres.2014.04.006

52. Ding Y, Li S, Ma R-L, et al. Association of homeostasis model assessment of insulin resistance, adiponectin, and low-grade inflammation with the course of the metabolic syndrome. Clin Biochem. 2015;48(7-8):503-507. doi:10.1016/j.clinbiochem.2015.02.005
53. Balogh A, Karpati E, Schneider AE, et al. Sex hormone-binding globulin provides a novel entry pathway for estradiol and influences subsequent signaling in lymphocytes via membrane receptor. Sci Rep. 2019;9(1):4. doi:10.1038/s41598-018-36882-3

54. Herman WA, Lącka K, Kaufman E, Wójcicka M, Kramer L, Losy J. The associations between iL-18 serum levels and the prevalence of metabolic syndrome in Polish men over the age of 40 according to other selected inflammatory indices and androgens: comparison of NCEP with IDF criteria. Exp Clin Endocrinol Diabetes Off J Ger Soc Endocrinol Ger Diabetes Assoc. 2011;119(7):423-430. doi:10.1055/s-0030-1270467

55. Simó R, Barbosa-Desongles A, Lecube A, Hernandez C, Selva DM. Potential role of tumor necrosis factor- $\alpha$ in downregulating sex hormone-binding globulin. Diabetes. 2012;61(2):372-382. doi:10.2337/ db11-0727

56. Kiortsis DN, Mavridis AK, Vasakos S, Nikas SN, Drosos AA. Effects of infliximab treatment on insulin resistance in patients with rheumatoid arthritis and ankylosing spondylitis. Ann Rheum Dis. 2005;64(5):765766. doi:10.1136/ard.2004.026534

57. Selva DM, Hogeveen KN, Innis SM, Hammond GL. Monosaccharideinduced lipogenesis regulates the human hepatic sex hormone-binding globulin gene. J Clin Invest. 2007;117(12):3979-3987. doi:10.1172/ JCI32249

58. Bhasin S, Jasjua GK, Pencina M, et al. Sex hormone-binding globulin, but not testosterone, is associated prospectively and independently with incident metabolic syndrome in men: the framingham heart study. Diabetes Care. 2011;34(11):2464-2470. doi:10.2337/ dc11-0888

59. Ding EL, Song Y, Manson JE, et al. Sex hormone-binding globulin and risk of type 2 diabetes in women and men. $N$ Engl J Med. 2009;361(12):1152-1163. doi:10.1056/NEJMoa0804381

60. Perry JRB, Weedon MN, Langenberg C, et al. Genetic evidence that raised sex hormone binding globulin (SHBG) levels reduce the risk of type 2 diabetes. Hum Mol Genet. 2010;19(3):535-544. doi: $10.1093 / \mathrm{hmg} / \mathrm{ddp} 522$

61. Svartberg J, Schirmer H, Wilsgaard T, et al. Single-nucleotide polymorphism, rs1799941 in the Sex Hormone-Binding Globulin (SHBG) gene, related to both serum testosterone and SHBG levels and the risk of myocardial infarction, type 2 diabetes, cancer and mortality in men: the Tromsø Study. Andrology. 2014;2(2):212-218. doi:10.1111/ j.2047-2927.2013.00174.x

62. Brand JS, Rovers MM, Yeap BB, et al. Testosterone, sex hormonebinding globulin and the metabolic syndrome in men: an individual participant data meta-analysis of observational studies. PLoS One. 2014;9(7):e100409. doi:10.1371/journal.pone.0100409

Diabetes, Metabolic Syndrome and Obesity: Targets and Therapy

Dovepress

Publish your work in this journal

Diabetes, Metabolic Syndrome and Obesity: Targets and Therapy is an international, peer-reviewed open-access journal committed to the rapid publication of the latest laboratory and clinical findings in the fields of diabetes, metabolic syndrome and obesity research. Original research, review, case reports, hypothesis formation, expert opinion and commentaries are all considered for publication. The manuscript management system is completely online and includes a very quick and fair peer-review system, which is all easy to use. Visit http://www.dovepress.com/testimonials.php to read real quotes from published authors. 